\title{
Investigation of the effect of coronary collateral circulation quality on postoperative atrial fibrillation after coronary artery bypass graft operations in patients with right coronary artery total occlusion
}

\author{
Mustafa Abanoz ${ }^{1}$, Şenol Yavuz ${ }^{2} \odot$ \\ ${ }^{1}$ Department of Cardiovascular Surgery, University of Health Sciences, Mehmet Akif Inan Training and Research Hospital, Şanluurfa, \\ Turkey \\ ${ }^{2}$ Department of Cardiovascular Surgery, University of Health Sciences, Bursa Medical Faculty, Bursa Yüksek Ihtisas Training and \\ Research Hospital, Bursa, Turkey
}

\begin{abstract}
Objectives: Postoperative atrial fibrillation (PoAF) may occur in $25-50 \%$ of patients after coronary artery bypass graft $(\mathrm{CABG})$ surgery. The severity of coronary artery disease and the quality of coronary collateral circulation (CCC) in the coronary artery with chronic total occlusion (CTO) are known as indirect indicators of myocardial ischemia. In this study, we aimed to investigate the effect of CCC quality on PoAF in patients with right coronary artery (RCA) total occlusion who underwent $\mathrm{CABG}$ operation.

Methods: Patients who underwent isolated CABG operation between May 15, 2016 and June 15, 2020 and had RCA CTO were included in the study retrospectively. The patients were recorded as Group 1 who developed PoAF in the postoperative period and Group 2 who did not.

Results: A total of 99 patients were included in the study. Those who develop PoAF were determined as Group $1(\mathrm{n}=32$, mean age $=66.9 \pm 11$ years $)$, and those who did not were determined as Group $2(\mathrm{n}=67$, mean age $=54.4 \pm 12.8$, years). There were no statistically significant differences between the two groups in terms of gender, smoking, diabetes mellitus, hypelipidemia and chronic obstuctive pulmonary disease rates. In multivariate analysis, being over 70 years old (OR: $1.396,95 \% \mathrm{CI}: 1.080-2.190, p=0.007)$, poor CCC (OR: 1.090, 95\% CI: $1.045-1.338, p=0.014$ ) and left atrial diamater (OR: 0.557, 95\% CI: $0.471-0.783, p=0.032$ ) were determined as independent predictors of development of PoAF.

Conclusions: In this current study, we demonstrated that low CCC quality increases the risk of POAF in patients with right coronary CTO. CCC quality can be used as an evaluation parameter in identifying groups at risk for PoAF in these special patient groups.

Keywords: Coronary artery disease, surgery, atrial fibrillation, coronary collateral circulation
\end{abstract}

C oronary artery bypass graft $(\mathrm{CABG})$ surgery is the most valuable method in the treatment of advanced coronary artery disease (CAD). Although mor- tality is a catastrophic risk in these operations, there are also morbid risks such as postoperative atrial fibrillation (PoAF), cognitive disorders, and end-organ coronary artery bypass graft operations in patients with right coronary artery total occlusion. Eur Res J 2022;8(2):175-181. DOI: 10.18621/eurj.1056188 Address for correspondence: Mustafa Abanoz, MD., University of Health Sciences, Mehmet Akif Inan Training and Research Hospital, Department of Cardiovascular Surgery, Esentepe Town, Ertugrul Street, Şanliurfa, Turkey.E-mail: mustafaabanozdr@hotmail.com, Tel: +9041431860 00, Fax:+90 4143186707 
damage [1]. Atrial fibrillation may occur in $25-50 \%$ of patients after CABG surgery. In addition, PoAF includes a cerebrovascular risk, prolongs hospitalizations and increases treatment costs [2]. Therefore, it is very important to reveal the risk factors for PoAF before $\mathrm{CABG}$ operations.

There are many factors that affect the development of PoAF after CABG surgery. These include inflammatory processes, advanced age, and perioperative ischemic events [3]. The severity of CAD and the quality of circulation in the coronary artery with chronic total occlusion (CTO) are known as indirect indicators of myocardial ischemia [4]. In a study, it was shown that preoperative poor coronary collateral circulation (CCC) increased the risk of PoAF after CABG operations [5]. Other studies have also shown that right coronary artery (RCA) disease or its severity is associated with PoAF $[6,7]$.

In this current study, we aimed to investigate the effect of CCC quality on PoAF in patients with RCA total occlusion who underwent $\mathrm{CABG}$ operation.

\section{METHODS}

Patients who underwent isolated CABG operation between May 15, 2016 and June 15, 2020 and had right coronary artery CTO were included in the study retrospectively. The study was initiated after the approval of the local ethics committee. The study was carried out in accordance with the Helsinki Declaration criteria. The data of the patients were obtained from the hospital digital record archive and patient files. Preoperative demographic characteristics (age, gender, comorbidities, etc.), operative (perfusion times) and postoperative (hospital and intensive care unit stays, inotropic needs, blood transfusion amounts, etc.) characteristics of all patients were recorded. Those who had emergency operations, combined cardiac surgeries, reoperations, those without RCA disease or rudimentary RCA, those who did not undergo right coronary bypass, those who used preoperative amiodarone, those with thyroid hormone disorders and those with atrial fibrillation were excluded from the study. As a result of exclusion criteria, 99 consecutive patients were included in the study. Coronary angiography of all patients was followed and the CCC of RCA was graded. The patients were recorded as Group
1 who developed PoAF in the postoperative period and Group 2 who did not. In the study, the factors affecting the risk of in-hospital PoAF after the operation were analyzed.

\section{Evaluation of Coronary Collateral Circulation}

Coronary collateral circulation was determined by the Rentrop classification. This evaluation was made by two individuals, an interventional cardiologist and a cardiovascular surgeon. Classification was performed as follows [5]: (a) Grade 0: No filling; (b) Grade 1: Inability to visualize the epicardial main vessel structure even though the lateral branches are filled with collaterals; (c) Grade 2: Partial filling of the epicardial main vessel structure with collaterals; and (d) Grade 3: Complete filling of the epicardial main vessel. As a result of this classification, patients with Grade 2 and Grade 3 fillings were included in the study. Right coronary bypass was performed in all patients.

\section{Diagnosis of Postoperative Atrial Fibrillation}

All patients were observed in the intensive care unit with continuous heart rhythm monitoring. Also, the 12-lead electrocardiography (ECG) was performed when the patients had complaints such as palpitation, dyspnea, or angina pectoris. Atrial fibrillation was verified via 12-lead ECG. The diagnosis of AF was based on guidelines of the European Society of Cardiology [8]. Postoperative atrial fibrillation was defined as irregular waves in place of typical $p$ waves on ECG. An AF episode $>60$ seconds was accepted as PoAF.

\section{Statistical Analysis}

In our study, SPSS 21.0 (IBM Statistical Package for the Social Sciences Statistic Inc. version 21.0, Chicago, IL, USA) program was used to analyze the data. Kolmogorov-Smirnov and Shapiro-Wilk tests were used to evaluate normality distribution. Continuous data and data with normal distribution were given as the mean and standard deviations. Data that did not distributed with normally were recorded as median (minimum-maximum). Student's t-test was used for the analysis of normally distributed data, while Mann Whitney U test was used for the analysis of non-normally distributed data. Frequency and percentile analysis were performed for nominal data and Chi 
Square test was used for comparison. Univariate and multivariate logistic regression analysis was performed to analyze the factors affecting the development of PoAF. A $p<0.05$ was considered statistically significant in all evaluations.

\section{RESULTS}

A total of 99 patients were included in the study. Those who develop PoAF were determined as Group $1(n=32$, mean age $=66.9 \pm 11$ years $)$, and those who did not were determined as Group $2(\mathrm{n}=67$, mean age $=54.4 \pm 12.8$, years). There were no statistically significant differences between the two groups in terms of gender, smoking, diabetes mellitus, hypelipidemia, chronic obstuctive pulmonary disease rates, cerebrovascular event/trans-ischemic attack history, body mass index, ejection fraction and beta blocker/angiotensin- converting enzyme inhibitor/angiotensin receptor blocker use rates. Rates of hypertension (HT), age and left atrial diamater were significantly higher in Group 1 compared with Group $2(P=0.007, p<$ 0.001 and $p=0.006$, respectively). Rentrop grade was significantly lower in Group $1(p<0.001)$. Demographic characteristics and preoperative data of all patients were summarized in Table 1.

Peroperative features of the patients were presented in Table 2 . There was no statistically significant difference between the two groups, in terms of perfusion times, blood product use rates and drainage amounts. Intensive care stay, total hospital stay days and positive inotropic support rates were statistically significantly higher in Group $1(p<0.001, p<0.001$ and $\mathrm{p}=0.023$ ).

Univariate and multivariate logistic regression analysis was utilized to predict parameters supporting development of PoAF (Table 3). In univariate analysis being over 70 years old (OR [odds ratio]: 1.921, 95\% CI [confidence interval]: 1.345-3.190, $p<0.001)$, hypertension (OR: 1.290, 95\% CI: 1.058-2.040, $p=$ 0.008), inotropic support (OR: $0.578,95 \%$ CI: 0.345 $0.776, p=0.024$ ), poor CCC (OR: $1.428,95 \% \mathrm{CI}$ : $1.145-1.944, p<0.001)$, and left atrial diameter (OR:

\section{Table 1. Demographic and preoperative features of the patients}

\begin{tabular}{|c|c|c|c|}
\hline Variables & $\begin{array}{l}\text { Group 1 } \\
(n=32)\end{array}$ & $\begin{array}{c}\text { Group 2 } \\
(n=67)\end{array}$ & $p$ value \\
\hline Age (years) (mean \pm SD) & $66.9 \pm 11$ & $54.4 \pm 12.8$ & $<0.001 \dagger$ \\
\hline Male gender, n (\%) & $23(71.9)$ & $40(59.7)$ & $0.239^{*}$ \\
\hline Smoking, n (\%) & $10(31.3)$ & $17(25.4)$ & $0.539^{*}$ \\
\hline Hypertension, n (\%) & $26(81.3)$ & $34(50.7)$ & $0.007^{*}$ \\
\hline Diabetes mellitus, n (\%) & $9(28.1)$ & $25(37.3)$ & $0.358^{*}$ \\
\hline Hyperlipidemia, n (\%) & $14(43.8)$ & $30(44.8)$ & $0.923^{*}$ \\
\hline COPD, n $(\%)$ & $7(9.9)$ & $6(16.6)$ & $0.144^{*}$ \\
\hline Previous CVA, n (\%) & $2(6.3)$ & $3(4.5)$ & $0.711^{*}$ \\
\hline $\operatorname{BMI}\left(\mathrm{kg} / \mathrm{m}^{2}\right)$ & $26.9(25-40.8)$ & $28.1(25-36.5)$ & $0.441^{\ddagger}$ \\
\hline Ejection fraction (\%) & $45(30-65)$ & $50(30-60)$ & $0.158^{\ddagger}$ \\
\hline$\beta$-Blocker therapy, $\mathrm{n}(\%)$ & $26(81.3)$ & $58(86.5)$ & $0.490^{*}$ \\
\hline ARB/ACE-I therapy, n (\%) & $9(28.1)$ & $17(24.4)$ & $0.614^{*}$ \\
\hline Left atrial diameter (mm) & $38(28-50)$ & $33(24-50)$ & 0.006 \\
\hline Rentrop state & & & $<0.001^{*}$ \\
\hline Grade 2, n (\%) & $22(68.7)$ & $18(26.8)$ & --- \\
\hline Grade 3, n (\%) & $10(31.2)$ & $49(73.1)$ & --- \\
\hline
\end{tabular}

Data are expressed as mean \pm SD or median (minimum-maximum) or n (\%). ${ }^{*}$ Chi-square test, $†$ Student's t-test, ${ }^{\ddagger}$ MannWhitney U test, ACE-I = angiotensin-converting enzyme inhibitor, ARB = angiotensin receptor blocker, BMI = Body mass index, $\mathrm{CVA}=$ Cerebrovascular accident, $\mathrm{COPD}=$ Chronic obstructive pulmonary disease, $\mathrm{SD}=$ standard deviation 
Table 2. Peroperative features of the patients

\begin{tabular}{lccc}
\hline Variables & $\begin{array}{c}\text { Group 1 } \\
(\mathbf{n = 3 2})\end{array}$ & $\begin{array}{c}\text { Group 2 } \\
(\mathbf{n = 6 7 )}\end{array}$ & $\boldsymbol{p}$ value \\
\hline Total perfusion time (min) & $88(60-130)$ & $85(55-120)$ & $0.304^{\ddagger}$ \\
Cross-clamp time (min) & $57(30-80)$ & $61(29-94)$ & $0.227^{\ddagger}$ \\
Inotropic support, n (\%) & $12(37.5)$ & $10(14.9)$ & $0.023^{*}$ \\
Packed blood products (units) & $5(4-13)$ & $5(4-10)$ & $0.219^{\ddagger}$ \\
Total chest tube drainage (ml) & $700(450-1500)$ & $850(400-1600)$ & $0.104^{\ddagger}$ \\
Total ICU stay (days) & $3(2-18)$ & $2(2-7)$ & $<\mathbf{0 . 0 0 1}^{\ddagger}$ \\
Total hospital stay (days) & $11(9-28)$ & $7(6-15)$ & $<\mathbf{0 . 0 0 1}^{\ddagger}$ \\
\hline
\end{tabular}

Data are expressed as median (minimum-maximum) or $\mathrm{n}(\%) .{ }^{*}$ Chi-square test, ${ }^{*}$ Mann-Whitney $\mathrm{U}$ test

$0.670,95 \%$ CI: $0.490-0.866, p=0.007$ ) were found to be significantly correlated with the development of PoAF. In multivariate analysis, being over 70 years old (OR: 1.396, 95\% CI: 1.080-2.190, $p=0.007$ ), poor CCC (OR: $1.090,95 \%$ CI: 1.045-1.338, $p=0.014$ ) and left atrial diamater (OR: 0.557, 95\% CI: 0.471-0.783, $p=0.032$ ) were determined as independent predictors of development of PoAF.

\section{DISCUSSION}

Coronary artery disease severity and poor CCC have also been implicated as indirect indicators of ischemic status [4]. Studies have shown that the prevalence of CAD increases the risk of PoAF after CABG operations [9]. Coronary collateral circulation is an adaptation mechanism developed by the heart against ischemia as a result of myocardial tissue being exposed to ischemia. As a result, the severity of ischemia suffered by the myocardial area with good collateral circulation will be less. It has been demonstrated that patients with good CCC have less tissue damage in myocardial infarction cases [10]. In a recent study, it was revealed that stroke and mortality rates after CABG operations are lower in patients with good CCC [11]. In this current study, we investigated the effect of CCC quality on PoAF in patient groups with RCA total occlusion. At the end of the study, we showed that poor CCC status is an independent predictor of PoAF after CABG operations, in addition to known risk factors such as being over 70 years of age and large left atrial diameter.

In a study by Gungor et al. [5], the role of CCC in predicting the development of PoAF after CABG operations was investigated. In their study, a total of 165

\section{Table 3. Logistic regression analysis to identify factors affecting development of postoperative atrial fibrillation}

\begin{tabular}{lcccccc}
\hline Variables & \multicolumn{3}{c}{ Univariate analysis } & \multicolumn{3}{c}{ Multivariate analysis } \\
& $\boldsymbol{p}$ value & $\begin{array}{c}\text { Exp(B) } \\
\text { Odds Ratio }\end{array}$ & $\begin{array}{c}\mathbf{9 5 \%} \text { CI } \\
\text { Lower-Upper }\end{array}$ & $\boldsymbol{p}$ value & $\begin{array}{c}\text { Exp(B) } \\
\text { Odds Ratio }\end{array}$ & $\begin{array}{c}\text { 95\% CI } \\
\text { Lower-Upper }\end{array}$ \\
\hline Age $>$ 70 years & $<\mathbf{0 . 0 0 1}$ & 1.921 & $1.345-3.190$ & $\mathbf{0 . 0 0 7}$ & 1.396 & $1.080-2.190$ \\
Hypertension & $\mathbf{0 . 0 0 8}$ & 1.290 & $1.058-2.040$ & 0.116 & 1.790 & $0.890-1.995$ \\
Diabetes mellitus & 0.376 & 0.990 & $0.770-1.180$ & -- & -- & -- \\
\hline COPD & 0.146 & 1.115 & $0.895-1.170$ & -- & -- & -- \\
Inotropic support & $\mathbf{0 . 0 2 4}$ & 0.578 & $0.345-0.776$ & 0.352 & 0.884 & $0.779-1.154$ \\
\hline Poor CCC & $<\mathbf{0 . 0 0 1}$ & 1.428 & $1.145-1.944$ & $\mathbf{0 . 0 1 4}$ & 1.090 & $1.045-1.338$ \\
\hline Left atrial diameter & $\mathbf{0 . 0 0 7}$ & 0.670 & $0.490-0.866$ & $\mathbf{0 . 0 3 2}$ & 0.557 & $0.471-0.783$ \\
\hline
\end{tabular}

$\mathrm{COPD}=$ Chronic obstructive pulmonary disease, $\mathrm{CCC}=$ Coronary collateral circulation 
patients were divided into two groups as those with poor CCC (Grade1 and 2, $\mathrm{n}=79$ ) and those with good CCC (Grade 2 and 3, $\mathrm{n}=89$ ). The incidence of PoAF was significantly higher in patients with poor CCC (37 [49\%] vs. 12 [14\%], $p<0.001)$. In the multivariate analysis, poor CCC was found to be an independent predictor of PoAF (OR: 11.500; 95\% CI, 3.977$33.253, p<0.001$ ) [5]. The effect of coronary vascular structure on PoAF was investigated in the study conducted by Polat et al. [12] in which 94 CABG patients were included. Although there was no statistically significant difference $(p=0.065)$, the rate of PoAF was found to be high in patients with poor CCC [12]. Unlike these two studies, we included only the patient group with RCA total occlusion, and all patients in our study underwent RCA bypass. Therefore, poor CCC Rentrop Grade 2 and good CCC Rentrop grade 3 were determined in our study. As a result of our study, we revealed poor CCC as an independent predictor of PoAF in patients who underwent $\mathrm{CABG}$ with right coronary collateral total occlusion.

Pathophysiological events that occur as a result of the exposure of the atrial wall to intraoperative ischemia may lead to the development of PoAF [13]. Although atrial branches may originate from the heads of the three main coronary arteries, RCA may contribute more to this supply [14]. In this direction, in the study by Mendes et al. in which 104 patients who underwent $C A B G$ were included, the patients with severe RCA stenosis $(>70 \%$ or $=70 \%)$ and those without it were divided into two groups and the risk factors for PoAF were investigated. At the end of this study, the authors revealed that severe RCA stenosis as an independent predictor of the development of PoAF in addition to factors such as age and male gender [6]. In a recent study, the relationship between right coronary artery disease severity calculated by Gensini score and PoAF in patients with RCA stenosis was investigated. In this retrospective study, which included $283 \mathrm{CABG}$ patients, right coronary artery disease with a high Gensini score was found to be an independent predictor of PoAF.

In our study, the presence of HT and positive inotropic support were also significantly correlated with the development of PoAF (OR: 1.290, $p=0.008$ and OR: $0.578, p=0.024)$. Hypertensive patient groups have increased inflammation status and these patients are also more vulnerable to myocardial ischemia. In a study, the frequency of atrial fibrillation was found to be approximately 1.6 times higher after CABG operations in hypertensive patients [15]. Positive inotropic support may also lead to atrial fibrillation due to increased sympathetic stimulation. Studies have shown that the use of increased positive inotropic support increases the risk of PoAF $[16,17]$.

In our study, in addition to the presence of poor CCC, other parameters that we showed independent predictors for PoAF were advanced age and left atrial diameter. Enlargements in the left atrial structure can also increase the risk of PoAF by causing various histopathological changes in the atrial conduction pathways and atrial structure. In a study by Karimi et al., its relationship with PoAF was also shown [18]. Structural and electrophysiological changes occur in the atrial tissue due to increased age. This situation also increases the risk of developing PoAF [18].

\section{Limitations}

Although our study included a special group of patients with RCA total occlusion, the limited number of patients is an important limitation. In addition, the study was conducted as a single center and retrospective study.

\section{CONCLUSION}

In conclusion, the most important treatment method of atherosclerotic heart disease is CABG operations. Atrial fibrillation is an important mortal and morbid condition that can occur after these operations, and it is important to reveal the risk factors. In this current study, we demonstrated that low CCC quality increases the risk of PoAF in patients with right coronary CTO. Collateral circulation quality can be used as an evaluation parameter in identifying groups at risk for PoAF in these special patient groups. Our study needs to be supported by multicenter prospective studies with different patient groups.

\section{Authors' Contribution}

Study Conception: MA; Study Design: MA; Supervision: MA, SY; Funding: MA; Materials: MA, SY; Data Collection and/or Processing: MA; Statistical Analysis and/or Data Interpretation: MA, SY; Literature Review: MA, SY; Manuscript Preparation: MA, 
SY and Critical Review: MA, SY.

\section{Conflict of interest}

The authors disclosed no conflict of interest during the preparation or publication of this manuscript.

\section{Financing}

The authors disclosed that they did not receive any grant during conduction or writing of this study.

\section{REFERENCES}

1. Seo EJ, Hong J, Lee HJ, Son YJ. Perioperative risk factors for new-onset postoperative atrial fibrillation after coronary artery bypass grafting: a systematic review. BMC Cardiovasc Disord 2021;21:418.

2. Savran M, Engin M, Guvenc O, Yüksek HF, Sünbül SA, Turk T, et al. Predictive value of HATCH scoring and waist-to-height ratio in atrial fibrillation following coronary artery bypass operations performed with cardiopulmonary bypass. J Saudi Heart Assoc 2021;33:117-23.

3. Engin M, Ozsin KK, Savran M, Guvenc O, Yavuz S, Ozyazicioglu AF. Visceral adiposity index and prognostic nutritional index in predicting atrial fibrillation after on-pump coronary artery bypass operations: a prospective study. Braz J Cardiovasc Surg 2021;36:522-9.

4. Berry C, Balachandran KP, L'Allier PL, Lespérance J, Bonan $\mathrm{R}$, Oldroyd KG. Importance of collateral circulation in coronary heart disease. Eur Heart J 2007;28:278-91.

5. Gungor H, Eryilmaz U, Akgullu C, Zencir C, Kurtoglu T, Selvi $\mathrm{M}$, et al. Preoperative poor coronary collateral circulation can predict the development of atrial fibrillation after coronary artery bypass graft surgery. Coron Artery Dis 2013;24:572-6.

6. Mendes LA, Connelly GP, McKenney PA, Podrid PJ, Cupples LA, Shemin RJ, et al. Right coronary artery stenosis: an independent predictor of atrial fibrillation after coronary artery bypass surgery. J Am Coll Cardiol 1995;25:198-202.

7. Ata Y, Abanoz M. Predictive roles of right coronary artery disease severity and systemic immune inflammation index in predicting atrial fibrillation after coronary bypass operations in patients with right coronary artery disease. Heart Surg Forum 2021;24:E977-82.

8. Camm AJ, Kirchhof P, Lip GY, Schotten U, Savelieva I, Ernst $\mathrm{S}$, et al. European Heart Rhythm Association. European Association for Cardio-Thoracic Surgery Guidelines for the management of atrial fibrillation: the task force for the management of atrial fibrillation of the European Society of Cardiology (ESC). Eur Heart J 2010;31:2369-429.

9. Engin M, Aydin C. Investigation of the effect of HATCH score and coronary artery disease complexity on atrial fibrillation after on-pump coronary artery bypass graft surgery. Med Princ Pract 2021;30:45-51.

10. Charney R, Cohen M. The role of the coronary collateral circulation in limiting myocardial ischemia and infarct size. Am Heart J 1993;126:937-45.

11. Güngör H, Sivri F, Yıldırım BO, Çayırlı S, Demiroğlu Ö, Yeşilkaya CU, et al. The effects of preoperative coronary collateral circulation on cardiac-related events after coronary artery bypass graft surgery. Braz J Cardiovasc Surg 2021;36:25-31.

12. Polat A, Sahin I, Yucel C, Onur I, Dinckal H, Erentug V. Coronary vasculature and postoperative atrial fibrillation: a risk factor analysis. Turk Gogus Kalp Dama 2013;21:567-73.

13. Narducci ML, Pelargonio G, Rio T, Leo M, Di Monaco A, Musaico F, et al. Predictors of postoperative atrial fibrillation in patients with coronary artery disease undergoing cardiopulmonary bypass: a possible role for myocardial ischemia and atrial inflammation. J Cardiothoracic Vasc Anesth 2014;28:512-9.

14. James TN, Burch GE. The atrial coronary arteries in man. Circulation 1958; 17:90-8.

15. Vural Ü, Ağlar AA. What is the role of metabolic syndrome and obesity for postoperative atrial fibrillation after coronary bypass grafting? BMC Cardiovasc Disord 2019;19:147.

16. Salaria V, Mehta NJ, Abdul-Aziz S, Mohiuddin SM, Khan IA. Role of postoperative use of adrenergic drugs in occurrence of atrial fibrillation after cardiac surgery. Clin Cardiol 2005;28:131-5.

17. Omar A, Elshihy EM, Singer M, Zarif D, Dawoud O. Perioperative risk factors predisposing to atrial fibrillation after CABG surgery. Heart Surg Forum 2021;24:E402-6.

18. Karimi A, Goodarzynejad H, Mortazavi SH, Bina P, Jalali A, Omran AS, et al. Left atrial size; a missing component in scoring systems for predicting atrial fibrillation following coronary artery bypass surgery. Acta Cardiol Sin 2020;36:456-63. 